\title{
Research on Relevant Economic Law in the Development and Application of Artificial Intelligence Products
}

\author{
Guang Chai \\ Tianjin University, Tianjin, 300072
}

Keywords: artificial intelligence technology; product development; product application; economic law

\begin{abstract}
Artificial intelligence technology has a profound influence on all aspects of social life and brings great convenience to human beings. Like any new technology, artificial intelligence technology brings many conveniences to human life, also causes a lot of economic problems, for example, artificial intelligence products have property rights, their rights and obligations should be defined to follow the economic law. This paper discusses the related economic laws in the research and development of AI products, promoting the application and development of AI technology in a certain aspect.
\end{abstract}

\section{Introduction}

Artificial intelligence technology has been the rise in all aspects of our social life have a profound impact, such as expert system, intelligent robot, pattern recognition, intelligent view of translation in traffic, medical, fire protection, energy and other fields have brought great convenience [1]. But the application of the new generation of information technology, as well as the development of information and communication service industry, plays an important role in promoting economic prosperity [2-3]. However, the development and application of artificial intelligence products not only rely on the innovation and improvement of technology, but also need to adjust and standardize the legal system.

\section{The development and application of artificial intelligence technology}

\subsection{The definition of artificial intelligence}

AI technology is a new science which sprang up in the 1950s. It not only applied skillfully to technology, but also applied related technologies to products, and developed intelligent products [4]. He is a study of a technical discipline that is similar or partially similar to helping people to perform related activities and extend certain human intelligence. Artificial intelligence is to some extent imitating human beings, so the study of artificial intelligence is sometimes in the study of human beings. Americans in the study of Wang Zhineng Nelson had also this understanding of artificial intelligence, artificial intelligence is not difficult to understand, he is the study of how to learn, and how to use a technology [5-6]. Professor Winston has also published his own view. He first thought that AI technology is to study human beings first, to study how people think and act, and to model or even transcend human's thinking process and behaviour process by AI technology. From the above two points of view, we can get the basic content of artificial intelligence, that is, artificial intelligence is based on human intelligence, and constructs the theory and method of simulating human activities through technological means.

In practice, AI technology is a discipline that studies people and studies computer control. It is to make certain programs on computers behave like human beings, such as debate, driving, thinking, computing and so on [7]. The research of AI is not only about computer itself, but also involves philosophy, epistemology, computation, neurology, information theory, cybernetics, psychology and linguistics. In other words, the field covered by AI technology covers almost all disciplines of natural science and Social Sciences, and advances with other disciplines in order to achieve better 
development between them.

\subsection{Application of artificial intelligence technology}

Artificial intelligence (AI) is a cross discipline, with a wide range of contents, and intersects such as philosophy, mathematics statistics and so on. Its application field is also a lot, with its development, a variety of more innovative theories and technologies have emerged [8]. For now, the research and application directions of AI technology include: perception intelligence, thinking intellectualization, learning intelligence and behaviour intellectualization. The field of application of artificial intelligence technology is shown in figure 1.

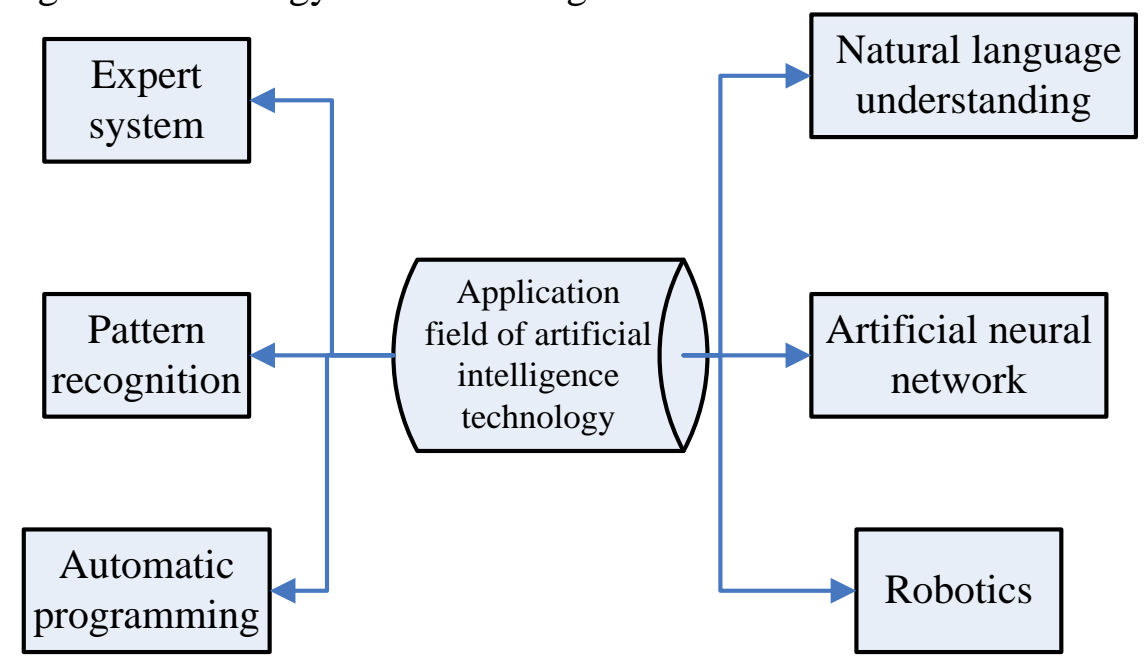

Figure 1. Application field of artificial intelligence technology

(1) Expert system.

The expert system is the most active part of the artificial intelligence system, and it is also one of the most breakthroughs from theory to practice. As the name suggests, the expert system is a program developed by human beings through intelligent technology, which has a relatively complete knowledge of a certain field, that is, the expert. By grasping relevant knowledge, we can help people solve problems in this field or replace people to perform certain behaviours [9]. Therefore, the expert system is not only a knowledge base, but also a reasoning machine. Therefore, with the expert system, related complex problems, we turned to the expert system of doctors, translation, lawyers and so on, and avoided a lot of trouble.

(2) Pattern recognition.

Just like human beings, when we distinguish something or object, we often find different places between objects and other things. At the same time, we classify and identify things that are similar but not identical. The apple is an abstract model, and the rich, the variety is the concretion of the pattern. Pattern recognition in this field can be understood by $\mathrm{W}$ as the surrounding environment and the object to be judged [10]. Pattern recognition is the function of integrating computer and mathematical knowledge into algorithm program to research and realize pattern recognition. At present, intelligent pattern recognition system has been more mature in public security system, such as fingerprint identification, form detection and so on.

(3) Automatic programming and natural language understanding.

Automatic program design is a new technology that presents some mechanical and objective programs through the program design. The purpose is to approach the mechanical work of the labour efficiency, will think of mistakes to a minimum. Automatic programming is widely used in the research and development of related software and in the repetitive pipelining work. Natural Language Processing, commonly known as human-computer dialogue, which is a branch of artificial intelligence [11]. It mainly studies how to identify human's usual communication language recognition, and tries to achieve natural communication between human and intelligent devices, that is to achieve communication between people and devices, just like human to human communication. In natural language understanding, at present, we have developed programs that can answer 
questions in English from the internal database, and these programs can also translate the text material from one language to another after reading the text material. The number of newly added enterprises in the field of artificial intelligence in China is shown in figure 2

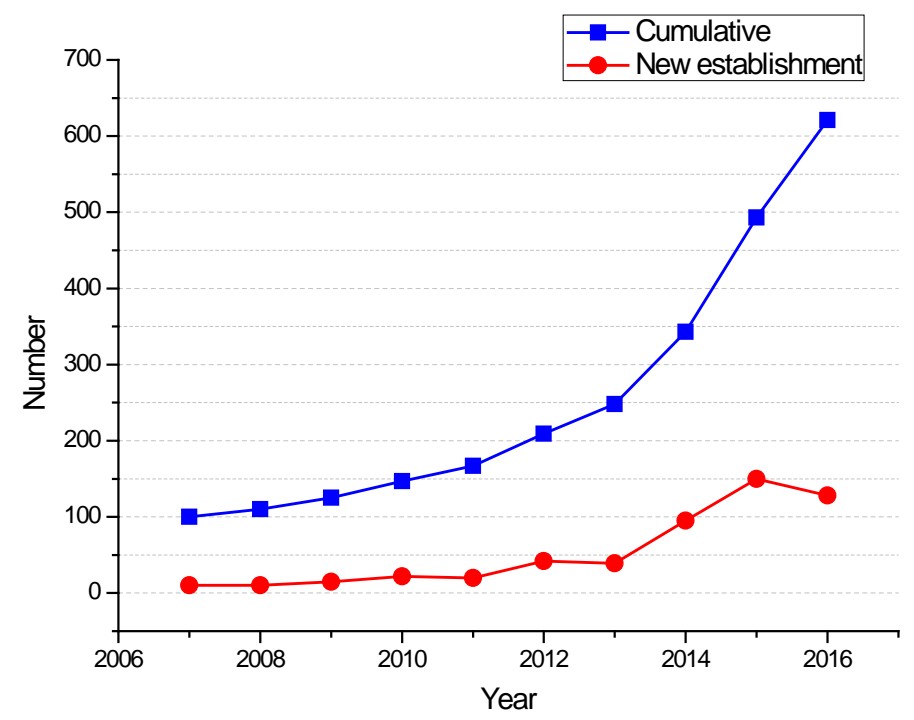

Figure 2. The number of new enterprises in the field of artificial intelligence in China

(4) Artificial neural network.

Artificial neural network is also referred to as neural network or connection model. This technology mainly studies the working principles and behaviour characteristics of animal's neural network, and develops corresponding algorithms and systems with technology. Artificial neural network technology is used to simulate the principle of neural work of one or more organisms, and then the intelligent technology is reproduced. Sometimes it can simulate brain intelligence and make some more advanced behaviour to solve more problems [12]. The neural network and its own advantages, and with the development of technology, will be recognized by more and more people.

(5) Robotics.

Robotics can also be called robotics or robotics. It focuses on the study of the functional realization of the humanlike nature of the robot and controls the relationship between the robot and the objects that communicate with them. There are many disciplines related to robotics, and related fields are also very wide. Related disciplines include kinematics, dynamics, sensing, control technology and action planning.

\section{Macro regulation and control method for artificial intelligence product development}

\subsection{Make clear plans to regulate and control power and responsibility and formulate plan law}

It is a necessary legal system to maintain the law's deterrence and ensure that the law is complied with and implemented. The responsibility of economic law is varied, including economic responsibility, responsibility of economic behaviour, responsibility of economic reputation, responsibility of economic management and economic criminal responsibility. Among them, the responsibility of economic management behaviour refers to the responsibility that the economic management obligor should bear in violation of the provisions of the economic law [13]. The plan is a general term for a country's planning and control departments to achieve macro regulation and control of the national economy through the formulation and implementation of the plan. The adjustment of the plan law is the economic relationship formed by the main body of the plan in the process of planning, examining and approving, executing and supervising.

\subsection{Promoting the construction of the technical standard system of the information industry}

The development of AI products is based on the research and innovation of IOT technology. Therefore, China's industrial policy focuses and supports the research and development of IOT from 
many aspects such as planning, finance and finance. In the era of information economy, the establishment of technical standards is related to the implementation of industrial technology policy, and more related to the adjustment of industrial structure and the realization of industrial organization policy. Moreover, because our country implements the product quality standardization management system, in the process of product quality standard management, supervision and inspection, the main basis is the quantified technical standard that should be achieved. Therefore, should be the technical standard system into the formulation and implementation of industrial technology policy law, planning, coordination of industry technical standards, with the promotion of technological innovation, technological transformation, the introduction of technology, high-tech research and development system of coordination, jointly as the main content of information industry law.

\subsection{Standardizing the information technology service of government procurement}

A professional government department is responsible for the quality evaluation of information technology service, or the service outsourcing to the social organization is responsible for the evaluation of the quality standard of information technology service. In the same way, the establishment of evaluation institutions should be based on the qualification of the evaluation institutions and the examination system for the qualification of the assessment personnel [14]. In addition to ensure the scientific and reasonable evaluation procedures, the establishment of information technology products and services, scientific and reasonable evaluation system, the provisions of the assessment of the application submitted to determine the assessment agencies and professional personnel as well as the evaluation of the effect of the, so as to guarantee the impartiality and professionalism of evaluation results.

\section{Market regulation method of artificial intelligence product application}

\subsection{The behaviour regulation of the main body of the Internet of things industry}

One of the basic principles of the market regulation law lies in the moderate intervention of the state. Market regulation law and macro control law cooperate closely. Rigid flexible cameras form indirect guidance and direct coordination with each other, which helps to fully realize the function of economic law. At present, the Internet of things industry is still in the initial stage of development. The business model of the Internet of things has not yet formed. It needs a positive policy support and a relatively loose market environment. Therefore, it is necessary to give more freedom to its economic activities when regulating the behaviour of the Internet of things industry.

\subsection{Making full use of the product quality inspection system}

The product quality inspection system is stipulated in our product quality legal system. At present, the national standard and industry standard of IOT are still in the process of further research and compilation. Under the absence of the state standards and industry standards, the role of the enterprise in the formulation of standards should be fully played. Enterprises will focus on industrial technology research and development, in order to ensure the quality of the Internet of things can be in a controllable and safe range. By comparing the basic technical data and combining the environment and security requirements of the product application, it provides a guarantee for the practical application of the Internet of things.

\subsection{Protecting consumer personal information}

The law of the protection of consumer rights and interests stipulates that the country and the society bear the responsibility of protecting the rights and interests of consumers, and make clear the right to protect the consumer's personal information in the rights and interests of the consumers. The protection of consumers' personal information and operator's protection obligations to consumers' personal information and personal information protection dispute settlement and legal liability are included in the consumer rights protection system that has been established into a certain system. It is of practical significance for the purpose of implementing personal information 
protection in consumer consumption and business management activities.

\section{Conclusions}

The development of law must find a balance between maintaining the consistency of existing laws and political events, adjusting and adapting to the new environment generated by the rapid social and economic changes. The profound connotation of AI is to improve the urban public service more scientifically and effectively through the intellectualization and informatization of the urban public management system, so as to achieve the sustainable development of AI research and development.

\section{References}

[1] Nissan E. Digital technologies and artificial intelligence's present and foreseeable impact on lawyering, judging, policing and law enforcement[J]. Ai \& Society, 2017, 32(3):1-24.

[2] Dowd T J, Dobbin F. The Embedded Actor and the Invention of Natural Economic Law: Policy Change and Railroader Response in Early America[J]. Social Science Electronic Publishing, 2014, 40(4):478-489.

[3] Dong S L. Analysis on the Application of Artificial Intelligence Technology in the Construction of the Internet Interactive Platform of Inquiry Curriculum[J]. 2016.

[4] Wu H T, Hsiao W T, Lin C T, et al. Application of genetic algorithm to the development of artificial intelligence module system[C]// International Conference on Intelligent Control and Information Processing. IEEE, 2011:290-294.

[5] Kamperman Sanders A. The principle of national treatment in international economic law : trade, investment and intellectual property[J]. Physiology \& Behavior, 2014, 55(5):839-844.

[6] Kennedy D. The International Style in Postwar Law and Policy: John Jackson and the Field of International Economic Law[J]. American University International Law Review, 2014(2).

[7] Marchand N, Jacobsen H A. An Economic Model to Study Dependencies between Independent Software Vendors and Application Service Providers[J]. Electronic Commerce Research, 2001, 1(3):315-334.

[8] Brand R A. Direct Effect of International Economic Law in the United States and the European Union[J]. Social Science Electronic Publishing, 2014(1).

[9] Garcia. Global Justice and International Economic Law Hardback[J]. International Economic Law, 2013.

[10] Exporters M E O. Law and Order, Business Climate, Economic Freedom and Country Risk[J]. Middle East Oil Exporters, 2006.

[11] Fuentes X. International Law-Making in the Field of Sustainable Development: The Unequal Competition Between Development and the Environment[J]. International Environmental Agreements, 2002, 2(2):109-133.

[12] Han L, University P. On the Economic Law Attribution and Application of "Law of Immediate Application” [J]. Journal of Beijing Institute of Technology, 2017.

[13] You Y Q. Construction and Application Network to Economic Law Teaching[J]. Advanced Materials Research, 2014, 926-930:4473-4476.

[14] Dyson T, Konstadinides T. The Application of EU Law in Defence Collaboration and Armament Procurement[J]. 2013. 